\title{
Changes in the crown angulation and dental arch widths after nonextraction orthodontic treatment: Model analysis of mild crowding with high canines
}

\author{
Morio Masunaga ${ }^{1 *}$, Hiroshi Ueda ${ }^{2}$, Kazuo Tanne $^{2}$ \\ ${ }^{1}$ Orthodontist in Private Practice, Osaka, Japan \\ ${ }^{2}$ Department of Orthodontics and Craniofacial Developmental Biology, Graduate School of Biomedical Sciences, Hiroshima Univer- \\ sity, Hiroshima, Japan \\ Email: ${ }^{*}$ stream@skyblue.ocn.ne.jp
}

Received 23 May 2012; revised 23 June 2012; accepted 6 July 2012

\begin{abstract}
This study was undertaken to examine which factors contributed to the correction of crowding in two patients who underwent nonextraction orthodontic treatment. A study model analysis was conducted to determine the effects of the orthodontic treatment for crowding with high canines on crown angulation and dental arch width in two patients. The results showed that the crown angulation was significantly increased, indicating distal tipping in the maxillary dental arch. This tendency was most commonly observed in the premolars among the lateral teeth. With respect to the dental arch width, the largest change was evident in the first molar and first premolar regions in cases 1 and 2, respectively. On the basis of these results, uprighting of mesially tipped lateral teeth and expansion of narrow dental arches could prove to be the keys to the success of space regaining or correction of high canines and mild crowding.
\end{abstract}

Keywords: Crowding; High Canine; Crown Angulation; Dental Arch Width; Model Analysis

\section{INTRODUCTION}

Crowding can be defined as a malocclusion with irregularly positioned teeth caused by tooth-jaw discrepancy; clinically, it has a comparatively high incidence among the various malocclusions [1-4]. Crowding can be treated via a variety of orthodontic procedures. For example, the extraction of permanent teeth $[5,6]$ and mesiodistal reduction of crown size $[7,8]$ are procedures designed to reduce the total tooth mass to facilitate alignment of the dental arches. Conversely, functional appliances [9] and palatal expansion $[10,11]$ can be utilized to expand the dental arches to accommodate the existing teeth. This

${ }^{*}$ Corresponding author. study was undertaken to examine which factors contributed to the correction of crowding in two patients who underwent nonextraction orthodontic treatment.

\section{MATERIALS AND METHODS}

\subsection{Case 1}

\subsubsection{History and Diagnosis}

A Japanese girl aged 10 years 4 months presented with a chief complaint of a high canine on the right side and anterior crowding. She had a symmetric face and straight facial profile (Figure 1(a)). The molar relationship was Angle Class I bilaterally. The overjet and overbite were $+2.0 \mathrm{~mm}$ (Figure 2(a)). The intraoral view showed a slightly narrow maxillary arch. The arch length discrepancies were estimated to be 3.0 and $1 \mathrm{~mm}$ in the upper and lower dental arches, respectively (Figure 3(a)).

Panoramic radiography confirmed the absence of root resorption (Figure 4(a)). Cephalometric analysis indicated the following angles: SNA, $80.0^{\circ}$; SNB, $76.0^{\circ}$; and ANB, $4.0^{\circ}$. FMA was $31.5^{\circ}$. The maxillary incisors were proclinedi by $119.0^{\circ}$ and $110.5^{\circ}$ to the $\mathrm{FH}$ and SN planes, respectively. With regard to the soft tissue, the distance from the lower lip to the $\mathrm{E}$ line was greater than that from the upper lip to the $\mathrm{E}$ line (Table 1). The diagnosis was Angle Class I malocclusion with a high canine on the right side.

\subsubsection{Treatment and Progress}

The treatment objectives were to correct the high canine and anterior crowding and achieve a functionally optimal occlusion without premolar extraction (T1). A $0.018 \times$ 0.025 -in standard edgewise appliance was placed on both dental arches. A series of Ni-Ti wires such as 0.014-, $0.016-$, and 0.018 -in round wires were used for leveling. Finally, the ideal $0.016 \times 0.022$-in arch wires were used for both dental arches. The active treatment lasted for 24 
months (T2; Figures 1(b), 2(b), 3(b) and 4(b)). After removal of the edgewise appliances, a Hawley-type retainer on the upper dental arch and a canine-to-canine spring retainer on the lower dental arch were placed. After 2 years of retention, acceptable occlusion was achieved (T3; Figures 1(c), 2(c), 3(c) and 4(c)).

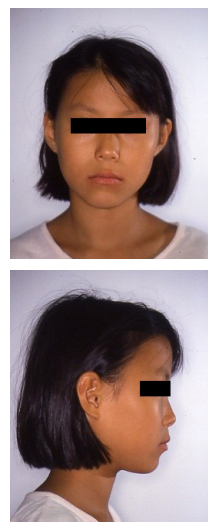

(a)
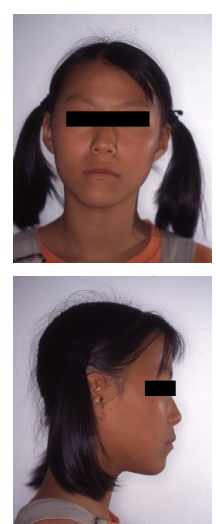

(b)
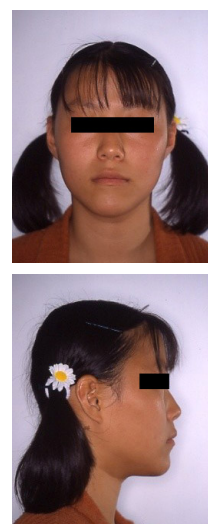

(c)
Figure 1. Facial photographs of patient 1: (a) pretreatment; (b) posttreatment; and (c) postretention.
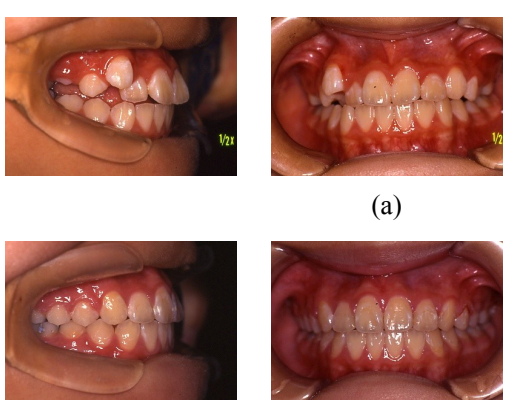

(a)

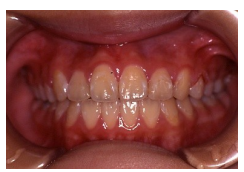

(b)
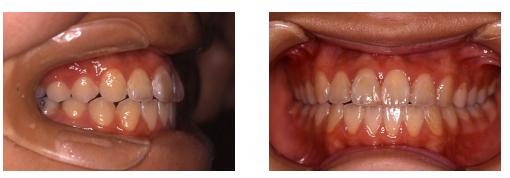

(c)

Figure 2. Intraoral photographs of patient 1 (centric occlusion): (a) Pretreatment; (b) Posttreatment; and (c) Postretention.

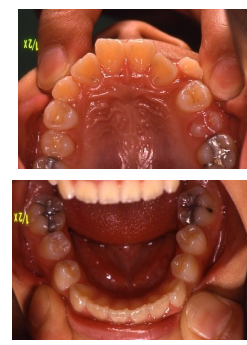

(a)
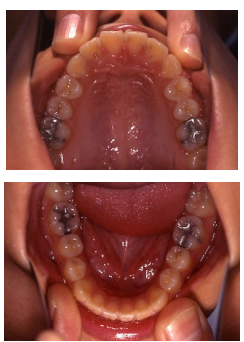

(b)
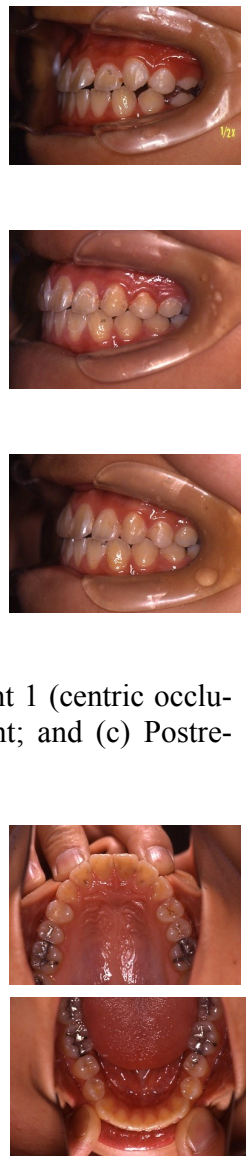

(c)
Figure 3. Occlusal view of patient 1: (a) Pretreatment; (b) Posttreatment; and (c) Postretention.

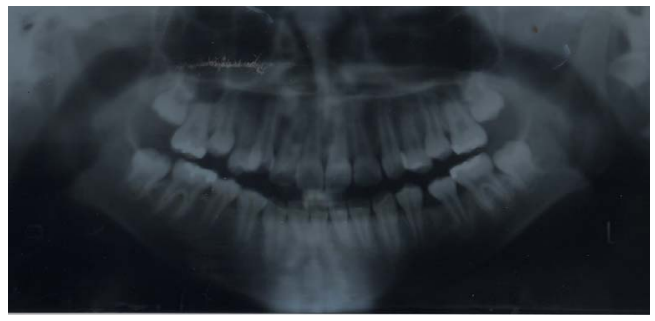

(a)

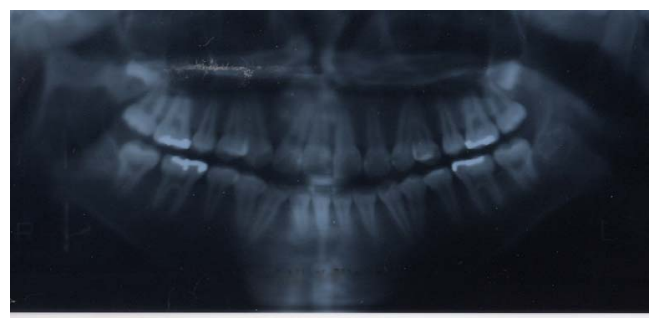

(b)

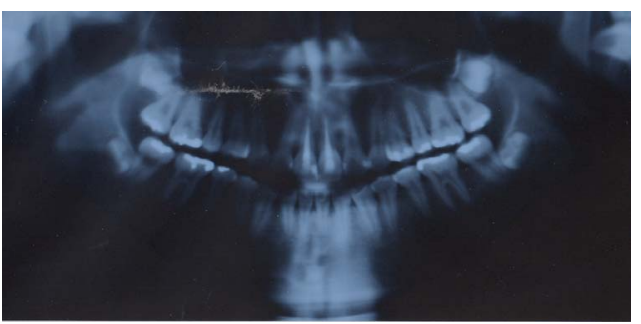

(c)

Figure 4. Panoramic radiographs of patient 1: (a) Pretreatment; (b) Posttreatment; and (c) Postretention.

Table 1. Summary of cephalometric analysis.

\begin{tabular}{|c|c|c|c|}
\hline Case 1 & $\mathrm{~T} 1$ & $\mathrm{~T} 2$ & $\mathrm{~T} 3$ \\
\hline & $(10$ y $4 \mathrm{mo})$ & $(12$ y $5 \mathrm{mo})$ & $(14$ y $5 \mathrm{mo})$ \\
\hline SNA $\left({ }^{\circ}\right)$ & 80.0 & 80.0 & 80.0 \\
\hline $\operatorname{SNB}\left({ }^{\circ}\right)$ & 76.0 & 77.5 & 78.5 \\
\hline $\operatorname{ANB}\left({ }^{\circ}\right)$ & 4.0 & 2.5 & 1.5 \\
\hline Facial A. $\left({ }^{\circ}\right)$ & 85.5 & 85.5 & 88.0 \\
\hline $\mathrm{Y}$-axis $\left({ }^{\circ}\right)$ & 65.0 & 66.5 & 64.5 \\
\hline Occ. Pl. $\left({ }^{\circ}\right)$ & 16.5 & 17.0 & 15.0 \\
\hline $\operatorname{FMA~}\left(^{\circ}\right)$ & 31.5 & 31.5 & 30.5 \\
\hline Gonial A. $\left({ }^{\circ}\right)$ & 125.5 & 124.0 & 124.0 \\
\hline $\mathrm{U} 1$ to $\mathrm{SN}\left({ }^{\circ}\right)$ & 110.5 & 99.0 & 102.5 \\
\hline $\mathrm{U} 1$ to $\mathrm{FH}\left({ }^{\circ}\right)$ & 119.0 & 107.5 & 111.0 \\
\hline FMIA $\left({ }^{\circ}\right)$ & 54.0 & 52.5 & 60.0 \\
\hline $\operatorname{IMPA}\left({ }^{\circ}\right)$ & 94.5 & 96.0 & 89.5 \\
\hline L1-Apo (mm) & 4.5 & 5.5 & 5.0 \\
\hline Upper lip to E line (mm) & 2.0 & 2.5 & 1.5 \\
\hline Lower lip to E line (mm) & 4.0 & 4.0 & 0.5 \\
\hline
\end{tabular}




\subsection{Case 2}

\subsubsection{History and Diagnosis}

A Japanese girl aged 11 years 11 months presented with a chief complaint of bilateral high canines and anterior crowding. She had a symmetric face and straight facial profile (Figure 5(a)). The molar relationship was Angle Class I on both sides. The overjet and overbite were +2.5 and $+2.0 \mathrm{~mm}$, respectively (Figure 6(a)). Her upper dental arch was slightly narrow, but both dental arches were approximately symmetrical. The arch length discrepancies were 3.0 and $1 \mathrm{~mm}$ in the upper and lower dental arches, respectively (Figure 7(a)).

Panoramic radiography confirmed the presence of all the third molars and absence of root resorption (Figure 8(a)). Cephalometric analysis indicated the following angles: SNA, $77.4^{\circ}$; SNB, $76.4^{\circ}$; and ANB, $1.0^{\circ}$. The FMA was $34.5^{\circ}$. The maxillary incisors were proclined by $119.4^{\circ}$ and $113.9^{\circ}$ to the $\mathrm{FH}$ and SN planes, respecttively. Of the soft tissue measurements, the distance from the lower lip to the $\mathrm{E}$ line was larger than that from the upper lip to the E line (Table 2). The diagnosis was skeletal Class I malocclusion with high canines and mild crowding.

\subsubsection{Treatment and Progress}

The treatment objectives were to correct the high canines and anterior crowding and achieve suitable functional occlusion without premolar extraction (T1). Standard edgewise appliances $(0.018 \times 0.025$ in $)$ were placed on both dental arches. Leveling was performed by using a series of Ni-Ti wires, including 0.014-, 0.016-, and 0.018 -in round wires. Finally, the ideal $0.016 \times 0.022$-in arch wires were applied to both dental arches. The active treatment time was 17 months (T2; Figures 5(b)-8(b)). After removal of the edgewise appliances, a Hawley-type retainer on the maxilla and a canine-to-canine spring retainer on the mandible were used. After 14 months of retention, occlusal relation was nearly achieved (T3; Figures $5(c)-8(c))$.

\subsubsection{Measurements of Crown Angulation}

A study model analysis was conducted to evaluate the effectiveness of the orthodontic treatment. A protractor with an adjustable readout arm (Shinwa Co. Ltd, Sanjyo, Japan) was used to measure the crown angulations (Figure 9). The crown angulations [11] were measured with reference to the posterior angle between the occlusal plane and the long axis of the clinical crown of canines, premolars, and first molars (Figure 10). The measurements read on the protractor's scale were evaluated to quantify the crown angulations in the upper and lower arches. All the measurements were conducted and recorded by one of the authors.

\subsubsection{Measurement of the Dental Arch Widths}

A sliding digital caliper (Mitsutoyo Co. Ltd., Kawasaki, Japan) with a precision of $\pm 0.02 \mathrm{~mm}$ was used to measure the dental arch widths. All the measurements were conducted and recorded by one of the authors. The reference points and landmarks are shown in Figure 11. The intermolar (the distance between the buccal groove
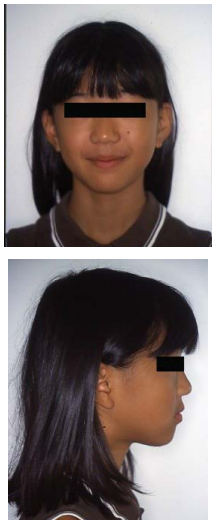

(a)
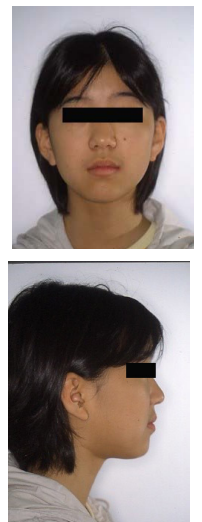

(b)

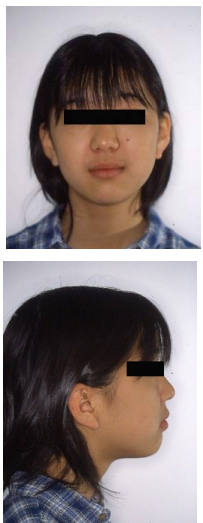

(c)
Figure 5. Facial photographs of patient 2: (a) Pretreatment; (b) Posttreatment; and (c) Postretention.
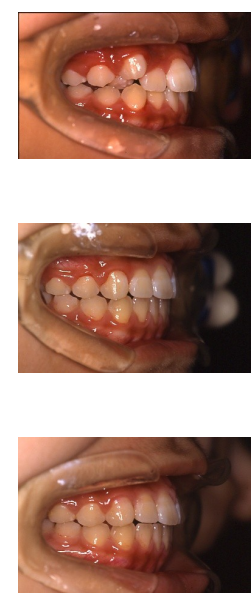
ment; (b) Posttreatment; and (c) Postretention.
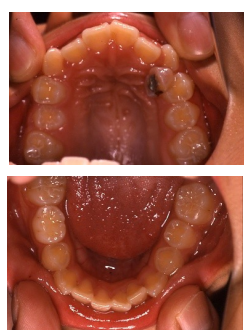

(a)

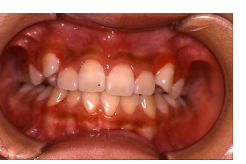

(a)

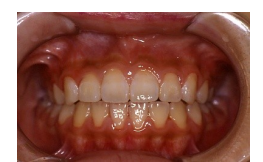

(b)

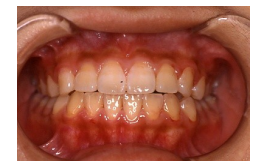

(c)
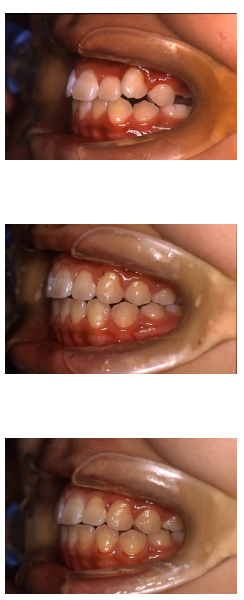

(a) Pretreat-
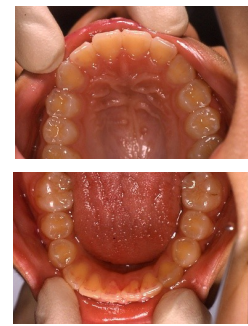

(b)

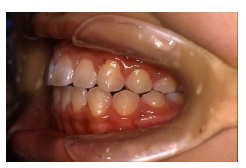

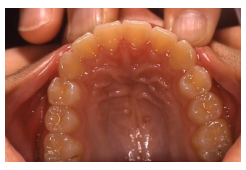

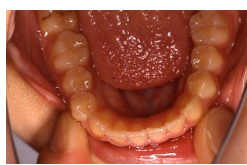

(c)
Figure 7. Occlusal view of patient 2: (a) Pretreatment; (b) Posttreatment; and (c) Postretention. 


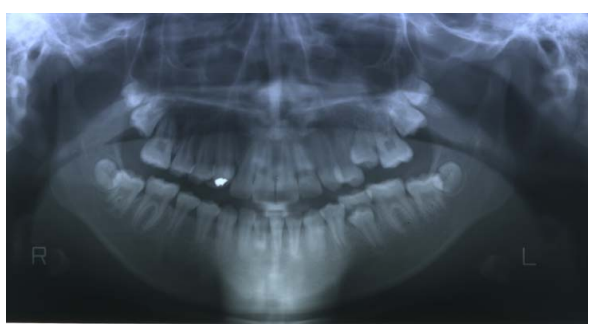

(a)

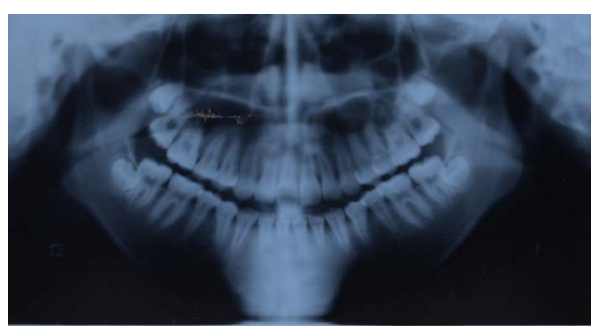

(b)

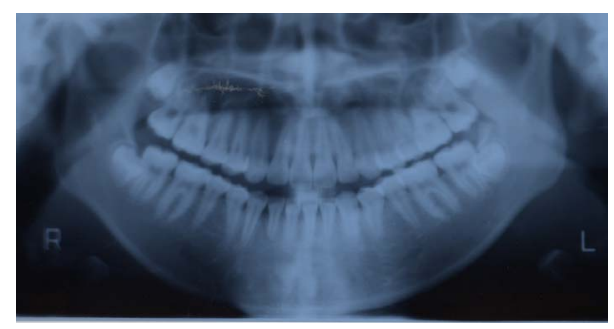

(c)

Figure 8. Panoramic radiographs of patient 2: (a) Pretreatment; (b) Posttreatment; and (c) Postretention.

Table 2. Summary of cephalometric analysis.

\begin{tabular}{|c|c|c|c|}
\hline Case 2 & $\begin{array}{c}\mathrm{T} 1 \\
(11 \mathrm{y} 11 \mathrm{mo})\end{array}$ & $\begin{array}{c}\mathrm{T} 2 \\
(13 \text { y } 6 \mathrm{mo})\end{array}$ & $\begin{array}{c}\mathrm{T} 3 \\
(14 \text { y } 8 \mathrm{mo})\end{array}$ \\
\hline SNA $\left(^{\circ}\right)$ & 77.4 & 77.4 & 76.5 \\
\hline $\operatorname{SNB}\left({ }^{\circ}\right)$ & 76.8 & 75.9 & 76.2 \\
\hline $\operatorname{ANB}\left({ }^{\circ}\right)$ & 0.6 & 1.5 & 0.3 \\
\hline Facial A. $\left({ }^{\circ}\right)$ & 82.8 & 81.7 & 78.5 \\
\hline $\mathrm{Y}$-axis $\left({ }^{\circ}\right)$ & 66.6 & 67.3 & 68.1 \\
\hline Occ. Pl. $\left({ }^{\circ}\right)$ & 16.4 & 17.2 & 17.8 \\
\hline FMA $\left({ }^{\circ}\right)$ & 34.5 & 35.5 & 36.6 \\
\hline Gonial A. $\left({ }^{\circ}\right)$ & 127.1 & 122.8 & 128.5 \\
\hline $\mathrm{U} 1$ to $\mathrm{SN}\left({ }^{\circ}\right)$ & 119.4 & 119.3 & 114 \\
\hline $\mathrm{U} 1$ to $\mathrm{FH}\left({ }^{\circ}\right)$ & 113.9 & 113.9 & 118.9 \\
\hline FMIA $\left({ }^{\circ}\right)$ & 58.3 & 51.9 & 53.0 \\
\hline $\operatorname{IMPA}\left({ }^{\circ}\right)$ & 87.2 & 92.6 & 90.4 \\
\hline L1-Apo (mm) & 4.6 & 5.5 & 6.5 \\
\hline Upper lip to E line (mm) & -2.0 & -0.7 & -0.9 \\
\hline Lower lip to E line (mm) & 0.7 & 2.4 & 1.7 \\
\hline
\end{tabular}

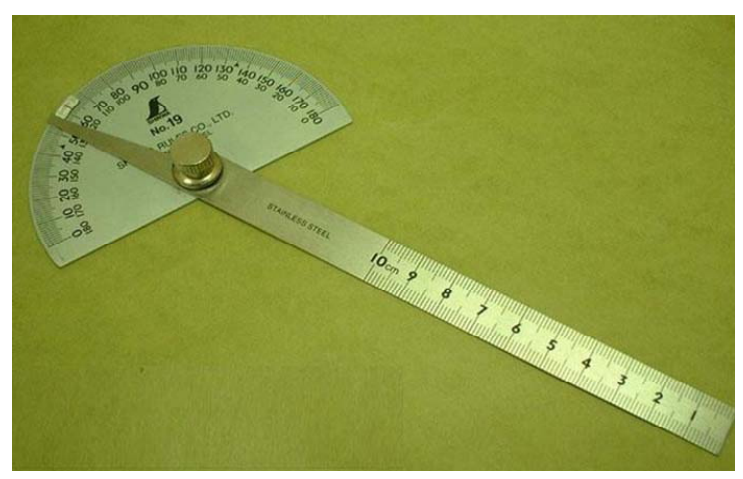

Figure 9. The protractor with the adjustable readout arm.
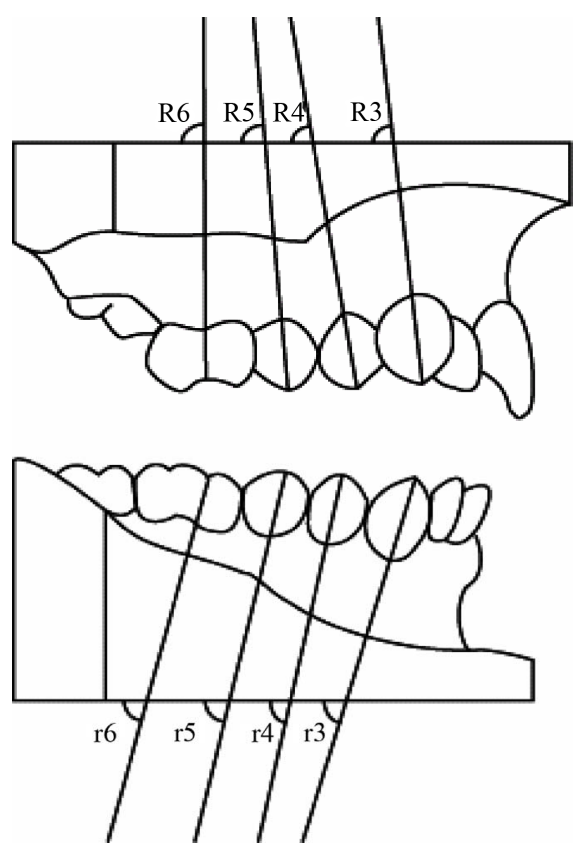

Figure 10. Crown angulation measurements.

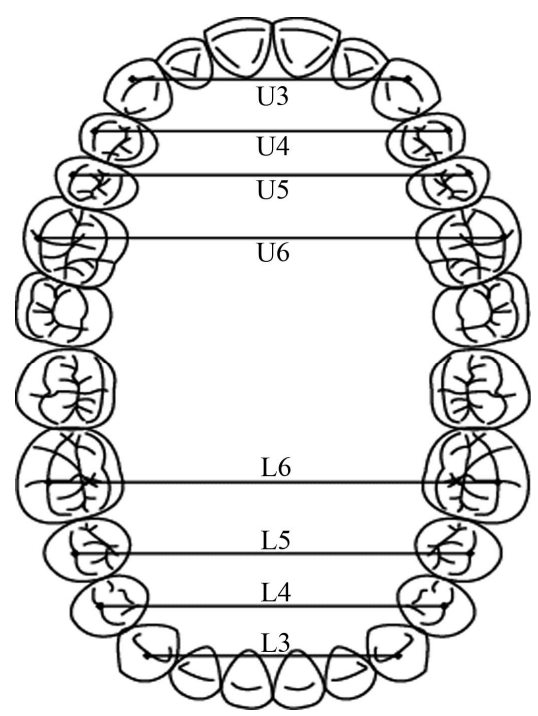

Figure 11. Illustration of the dental arch width measurement. 
at the buccal and occlusal surface interface of the bilateral first molars), interpremolar (the distance between the buccal cusps of the bilateral premolars), and intercanine widths (the distance between the buccal cusps of the bilateral canines) were measured to quantify the changes in the upper and lower dental arches.

\section{RESULTS}

\subsection{Treatment Results}

\subsubsection{Case 1}

After the active treatment, acceptable occlusion and facial profile were achieved (Figures 1(b) and 2(b)). The posttreatment panoramic radiograph showed that the roots were parallel, without resorption or periodontal bone loss (Figure 4(b)). The superimposed cephalometric tracings before and after the treatment illustrated the changes resulting from the treatment (Figure 12). The skeletal measurements did not show any significant changes. On the contrary, the maxillary incisors were inclined lingually to the FH plane, as was noted by the change from $119.0^{\circ}$ to $107.5^{\circ}$ and approached the Japanese norm. The mandibular incisor angulation was not significantly changed. There were no significant changes in the soft tissue measurements (Table 1). The intercuspation remained stable, and a harmonious profile was maintained during the 2-year retention period, although slight labial tipping of the upper incisors and lingual tipping of the lower incisors due to mandibular growth were observed (Figure 2(c)).

\subsubsection{Case 2}

The edgewise appliances were used for 1 year 5 months. The facial profile was well maintained up to the end of the treatment (Figure 5(b)). The crowding was improved, with optimal overjet and overbite and bilateral Class I molar relation (Figure 6(b)). The panoramic radiograph taken after the treatment showed proper parallel alignment of the roots without signs of resorption or periodontal bone loss. Cephalometric superimposition showed slight growth of the mandible (Figure 13), but the changes were negligible. The mandibular incisors were proclined, as indicated by the change in the IMPA from $87.2^{\circ}$ to $92.6^{\circ}$, and approached the Japanese norm. The maxillary incisor angulation was not significantly changed (Table 2). Both the facial appearance and the occlusal condition were well maintained during the 14-month retention period (Figures 5(c), 6(c), and 7(c)).

\subsection{Changes in Crown Angulation}

In case 1, the axial angulation of the maxillary premolars, measured as the angle formed between the long axis of the clinical crown and the occlusal plane, increased from $71.5^{\circ}$ to $80.5^{\circ}$, indicating that the teeth showed mesial tipping. However, the upper first molars showed an approximately $90^{\circ}$ angle to the occlusal plane. In the lower dental arch, the premolars and first molars presented an angulation of $90^{\circ}$ to the occlusal plane. In particular, the upper first premolars on the right side, the same side as the high canine, showed uprighting after the treatment, with an increase in the axial angulation from $71.5^{\circ}$ to $87.5^{\circ}$. In contrast, the premolars and molars on the left side did not present any significant changes in axial

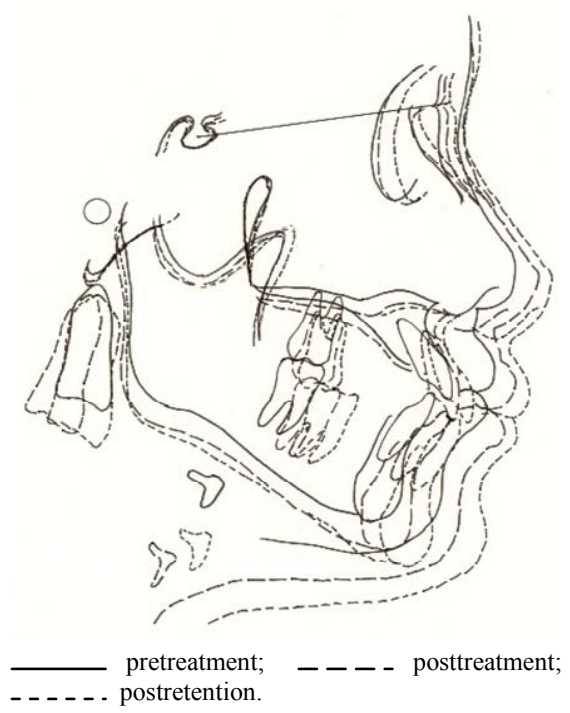

Figure 12. Superimposition of the cephalometric tracings on the $\mathrm{SN}$ plane at $\mathrm{S}$ in case 1 .

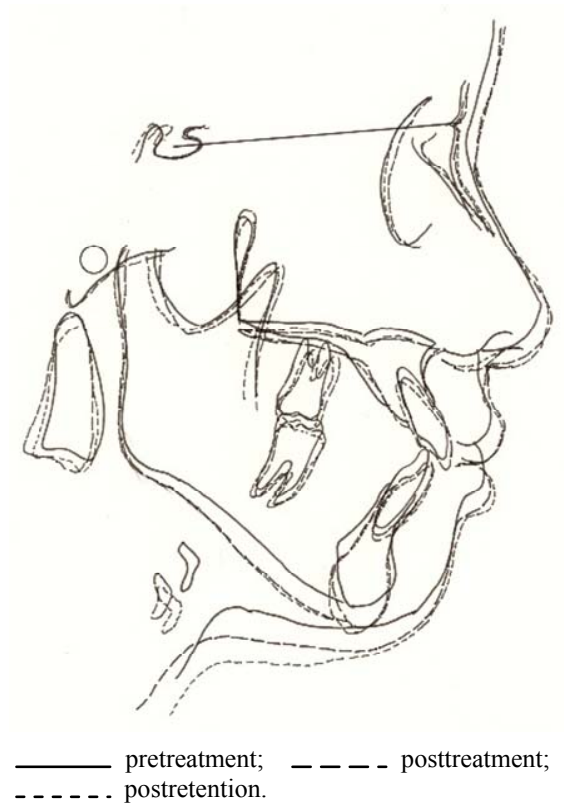

Figure 13. Superimposition of the cephalometric tracings on the $\mathrm{SN}$ plane at $\mathrm{S}$ in case 2 . 
angulation. Furthermore, the angulations of the lower premolars and first molars were unchanged (Table 3).

In case 2, the change in the axial angulation of the first premolar on the right side was the largest among the upper premolars and molars. The axial angulations of the lateral teeth increased on both sides, showing distal tipping. Conversely, most of the lower teeth did not present considerable changes $\left(-3.5^{\circ}\right.$ to $\left.+2.0^{\circ}\right)$, although the first molar on the left side showed mesial tipping of $10^{\circ}$ (Table 4).

Table 3. The crown angulation.

\begin{tabular}{|c|c|c|c|c|c|}
\hline & & Canine & 1st premolar & 2nd premolar & 1 st molar \\
\hline \multicolumn{6}{|c|}{ Case 1} \\
\hline \multicolumn{6}{|c|}{ Maxillary } \\
\hline & $\mathrm{T} 1$ & 97.5 & 80.5 & 81.5 & 86.5 \\
\hline \multirow[t]{3}{*}{ Left } & $\mathrm{T} 2$ & 83.5 & 85.5 & 90.5 & 88 \\
\hline & $\mathrm{T} 2-\mathrm{T} 1$ & -14.0 & 5.0 & 9.0 & 1.5 \\
\hline & $\mathrm{T} 1$ & 95 & 71.5 & - & 84.0 \\
\hline \multirow[t]{2}{*}{ Right } & $\mathrm{T} 2$ & 78.5 & 87.5 & 87 & 92.5 \\
\hline & $\mathrm{T} 2-\mathrm{T} 1$ & -16.5 & 16 & - & 8.5 \\
\hline \multicolumn{6}{|c|}{ Mandibular } \\
\hline & $\mathrm{T} 1$ & 89 & 95.0 & 85.0 & 90.0 \\
\hline \multirow[t]{3}{*}{ Left } & $\mathrm{T} 2$ & 90 & 96.0 & 85.0 & 87.5 \\
\hline & $\mathrm{T} 2-\mathrm{T} 1$ & 1.0 & 1.0 & 0 & -2.5 \\
\hline & $\mathrm{T} 1$ & 97.5 & 93.5 & 78.5 & 92.5 \\
\hline \multirow[t]{2}{*}{ Right } & $\mathrm{T} 2$ & 97.5 & 95.0 & 81.0 & 87.0 \\
\hline & $\mathrm{T} 2-\mathrm{T} 1$ & 0 & 1.5 & 2.5 & -5.5 \\
\hline
\end{tabular}

Table 4. The crown angulation.

\begin{tabular}{|c|c|c|c|c|c|}
\hline & & Canine & 1st premolar & 2nd premolar & 1st molar \\
\hline \multicolumn{6}{|c|}{ Case 2} \\
\hline \multicolumn{6}{|c|}{ Maxillary } \\
\hline & $\mathrm{T} 1$ & 75.0 & 80.5 & - & 86.5 \\
\hline \multirow[t]{3}{*}{ Left } & $\mathrm{T} 2$ & 81.5 & 82.5 & 83.5 & 87.5 \\
\hline & $\mathrm{T} 2-\mathrm{T} 1$ & 6.5 & 2.0 & - & 1.0 \\
\hline & $\mathrm{T} 1$ & 68.5 & 80.5 & 79.0 & 94.5 \\
\hline \multirow[t]{2}{*}{ Right } & $\mathrm{T} 2$ & 82.0 & 86.0 & 88.0 & 90.5 \\
\hline & $\mathrm{T} 2-\mathrm{T} 1$ & 13.5 & 5.5 & 9.0 & -4.0 \\
\hline \multicolumn{6}{|c|}{ Mandibular } \\
\hline & $\mathrm{T} 1$ & 87.5 & 85.5 & - & 94.5 \\
\hline \multirow[t]{3}{*}{ Left } & $\mathrm{T} 2$ & 86.0 & 87.5 & 84.5 & 84 \\
\hline & $\mathrm{T} 2-\mathrm{T} 1$ & -1.5 & 2.0 & - & -10.5 \\
\hline & $\mathrm{T} 1$ & 90.0 & 93.0 & 90.0 & 89.5 \\
\hline \multirow[t]{2}{*}{ Right } & $\mathrm{T} 2$ & 91.0 & 89.5 & 87.0 & 93.0 \\
\hline & $\mathrm{T} 2$ - T1 & 1.0 & -3.5 & -3.0 & 3.5 \\
\hline
\end{tabular}

\subsection{Changes in the Dental Arch Widths}

In case 1 , the upper and lower dental arches showed slightly decreased arch width at the canines. Conversely, the arch widths at the first premolars and first molars increased to 0.4 and $1.8 \mathrm{~mm}$, respectively. In the lower dental arch, the arch width at the first molars increased by $1.1 \mathrm{~mm}$ (Table 5 ).

In case 2, the changes in the arch width at the first premolars were the largest in the upper and lower dental arches (upper, $1.2 \mathrm{~mm}$; lower, $4.4 \mathrm{~mm}$ ). The changes in the first molar width were less than $1 \mathrm{~mm}$ in both dental arches (Table 5).

\section{DISCUSSION}

In the present study, a study model analysis was carried out to determine the effects of nonextraction orthodontic treatment for crowding with high canines on crown angulation and dental arch width. The results showed that the crown angulation was significantly increased, indicating distal tipping in the upper dental arch. This tendency was found mostly in the premolars among the lateral teeth. Therefore, high canines might occur because the canines normally erupt among the lateral teeth, although the space for eruption is insufficient. On the other hand, the significant mesial tipping of the crowns was demonstrated as a cause of high canines because uprighting of these teeth corrected the crowding.

Model analysis is a simple and easy method for dental clinicians. Its main advantage when compared with cephalometric analysis is that crown angulation can be measured. Further, on cephalograms, individual teeth on

Table 5. Dental arch widths.

\begin{tabular}{|c|c|c|c|c|c|}
\hline & & Canine & 1st premolar & 2nd premolar & 1st molar \\
\hline \multicolumn{6}{|l|}{ Case 1} \\
\hline \multirow{3}{*}{ Maxillary } & $\mathrm{T} 1$ & 37.1 & 42.6 & - & 54.0 \\
\hline & $\mathrm{T} 2$ & 34.5 & 43 & 49.1 & 55.8 \\
\hline & $\mathrm{T} 2$ - T1 & -2.6 & 0.4 & - & 1.8 \\
\hline \multirow{3}{*}{ Mandibular } & $\mathrm{T} 1$ & 28.0 & 34.1 & 39.5 & 45 \\
\hline & $\mathrm{T} 2$ & 26.2 & 34.6 & 39.6 & 46.1 \\
\hline & $\mathrm{T} 2-\mathrm{T} 1$ & -1.8 & 0.5 & 0.1 & 1.1 \\
\hline \multicolumn{6}{|l|}{ Case 2} \\
\hline \multirow{3}{*}{ Maxillary } & $\mathrm{T} 1$ & 35.2 & 40.9 & - & 49.6 \\
\hline & $\mathrm{T} 2$ & 35 & 42.1 & 46.2 & 49.7 \\
\hline & $\mathrm{T} 2$ - T1 & -0.2 & 1.2 & - & 0.1 \\
\hline \multirow{3}{*}{ Mandibular } & $\mathrm{T} 1$ & 25.8 & 31.9 & - & 44.1 \\
\hline & $\mathrm{T} 2$ & 26.5 & 36.3 & 40.8 & 43.4 \\
\hline & $\mathrm{T} 2$ - T1 & 0.7 & 4.4 & - & -0.7 \\
\hline
\end{tabular}




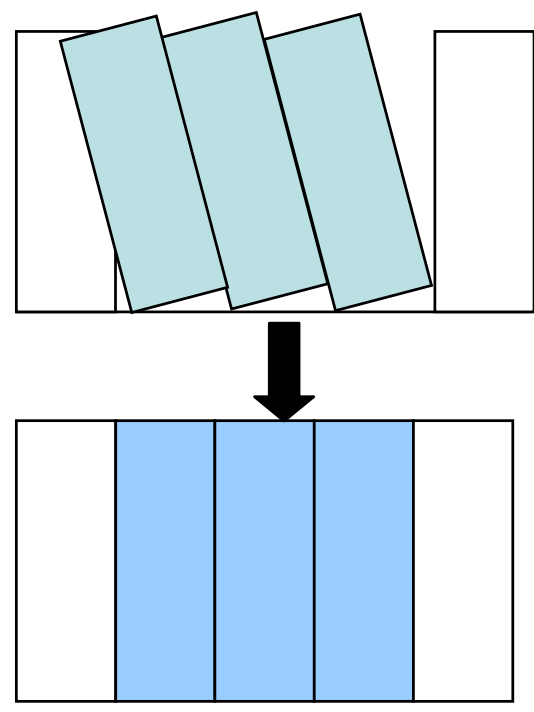

Figure 14. Schematic of the relationship between the crown angulation and crowding.

the right and left sides may be difficult to identify. Several studies of straight-wire appliances have been conducted to investigate the angulation of the tooth crown in study models. Andrews [12] and Sebata [13] measured the crown angulation in subjects with normal occlusion and found that the premolars and molars in the upper and lower dental arches tend to be upright to the occlusal plane, which is very similar to the results after the orthodontic treatment in this study.

With respect to the dental arch width, the largest change was observed in the regions of the first molars and premolars in cases 1 and 2, respectively. By comparing the dental arch between normal occlusion and crowding, Howe et al. [4] reported that the crowding cases showed narrower and more asymmetric arches than the controls. Moreover, the subjects with normal occlusion showed wide and U-shaped symmetric arches. Therefore, uprighting of mesially tipped lateral teeth and expansion of a narrow dental arch could be the keys to the success of space regaining or correction of high canines and mild crowding (Figure 14). If the discrepancy is excessive, the premolars should be extracted for treating severe crowding.

Finally, this study has certain limitations because of the very small sample size. A further investigation focusing on crown angulation and dental arch width in a larger number of cases of crowding with high canines is warranted.

In conclusion, discrepancies in crown size and basal arch length and width are traditionally examined. However, the orthodontist should analyze the dental arch in terms of crown angulation, buccolingual position of the crown, and dental arch width, by using three-dimensional imaging.

\section{REFERENCES}

[1] Van der Linden, F.P.G.M. (1974) Theoretical and practical aspects of crowding in the human dentition. Journal of the American Dental Association, 89, 139-153.

[2] Sakuda, M., Kuroda, Y., Wada, K. and Matsumoto, M. (1976) Changes in crowding of teeth during adolescence and their relation to the growth of the facial skeleton. Trans European Orthodontic Society (Special Edition), 93-104.

[3] Leighton, B.C. and Hunter, W.S. (1982) Relationships between lower arch spacing/crowding and facial height and depth. American Journal of Orthodontics, 82, 418425. doi:10.1016/0002-9416(82)90191-9

[4] Howe, R.P., McNamara, J.A. Jr. and O'Connor, K.A. (1983) An examination of dental crowding and its relationship to tooth size and arch dimension. American Journal of Orthodontics, 83, 363-373. doi:10.1016/0002-9416(83)90320-2

[5] Little, R.M., Wallen, T.R. and Riedel, R.A. (1981) Stability and relapse of mandibular anterior alignment-first premolar extraction cases treated by conventional edgewise orthodontics. American Journal of Orthodontics, 80, 349-365. doi:10.1016/0002-9416(81)90171-8

[6] Gorman, J.C. (1993) The effects of premolar extraction on the long-term stability of the mandibular incisors. In: Nanda, R. and Burstone, C.J. Eds., Retention and Stability in Orthodontics, W.B. Saunders Co., Philadelphia, 81-96.

[7] Sheridan, J.J. (2003) Air-rotor stripping. Journal of Clinical Orthodontics, 19, 43-59.

[8] Peck, S. and Peck, H. (1972) Crown dimensions and mandibular incisor crowding. The Angle Orthodontics, 42, 148-153.

[9] McDougall, P.D., McNamara, J.A. Jr. and Dierkes, J.M. (1982) Arch width development in class II patients treated with the Frankel appliance. American Journal of Orthodontics, 82, 10-22. doi:10.1016/0002-9416(82)90541-3

[10] Haas, A.J. (1961) Rapid expansion of the maxillary dental arch and nasal cavity by opening of the midpalatal suture. The Angle Orthodontics, 31, 73-90.

[11] Howe, R.P. (1982) Palatal expansion using a bonded appliance: Report of a case. American Journal of Orthodontics, 82, 464-468. doi:10.1016/0002-9416(82)90313-X

[12] Andrews, L.F. (1972) The six keys to normal occlusion. American Journal of Orthodontics, 62, 296-309. doi:10.1016/S0002-9416(72)90268-0

[13] Sebata, E. (1980) An orthodontic study of teeth and dental arch form on the Japanese normal occlusions. Shikwa Gakuho, 80, 945-969. 